Review

\title{
Biomarkers for Colorectal Cancer
}

\section{Takuji Tanaka $^{1,2, *}$, Mayu Tanaka ${ }^{3}$, Takahiro Tanaka ${ }^{4}$ and Rikako Ishigamori ${ }^{5}$}

1 The Tohkai Cytopathology Institute: Cancer Research and Prevention (TCI-CaRP), 5-1-2 MinamiUzura, Gifu 500-8285, Japan

2 Department Oncologic Pathology, Kanazawa Medical University, 1-1 daigaku, Uchinada Ishikawa 920-0293, Japan

3 Department of Pharmacy, Kinjo Gakuin University of Pharmacy, Moriyama-Ku, Nagoya, Aichi 463-8521, Japan

4 Department of Physical Therapy, Kansai University of Health Sciences, Kumatori-Machi, Sennan-Gun, Osaka 590-0482, Japan; E-Mail: tmntt08@ gmail.com

5 Cancer Prevention Basic Research Project, National Cancer Center Research Institute, Tokyo 104-0045, Japan; E-Mail: rishigam@ncc.go.jp

* Author to whom correspondence should be addressed; E-Mail: takutt@ toukaisaibou.co.jp or takutt@kanazawa-med.ac.jp; Tel.: +81-58-273-4399; Fax: +81-58-273-4392.

Received: 18 August 2010; in revised form: 2 September 2010 / Accepted: 3 September 2010 / Published: 13 September 2010

Abstract: Colorectal cancer (CRC) is the third most common epithelial malignancy in the world. Since CRC develops slowly from removable precancerous lesions, detection of the lesion at an early stage by regular health examinations can reduce the incidence and mortality of this malignancy. Colonoscopy significantly improves the detection rate of CRC, but the examination is expensive and inconvenient. Therefore, we need novel biomarkers that are non-invasive to enable us to detect CRC quite early. A number of validation studies have been conducted to evaluate genetic, epigenetic or protein markers for identification in the stool and/or serum. Currently, the fecal occult blood test is the most widely used method of screening for CRC. However, advances in genomics and proteomics will lead to the discovery of novel non-invasive biomarkers.

Keywords: biomarkers; colorectal cancer; fecal biomarkers; genomic and epigenetic biomarkers; serum biomarkers; microRNA 


\section{Introduction}

Various types of cancer biomarkers are listed in Table 1.

Table 1. Cancer biomarkers.

\begin{tabular}{|l|l|}
\hline Type of biomarkers & Analysis \\
\hline \multirow{2}{*}{ Genetic } & Gene mutations \\
\cline { 2 - 2 } & Tumor suppressor gene status \\
\hline \multirow{3}{*}{ DNA } & Gene amplification \\
\cline { 2 - 2 } & Microsatellite instability \\
\cline { 2 - 2 } & Mitochondrial DNA \\
\hline Epigenetic & DNA methylation \\
\hline RNA & microRNAs \\
\hline Protein & - \\
\hline Metabolic & - \\
\hline Immunological & T-cell and cytokine responses \\
\hline
\end{tabular}

Any measurable specific molecular alteration of a cancer cell either at the DNA, RNA, protein, or metabolite level can be referred to as a cancer biomarker. The expression of a distinct gene can enable its identification in a tissue in which none of the surrounding non-cancerous cells express the specific marker. It is difficult to distinguish related disease subtypes that have different clinical outcomes. There is therefore a need for more exact molecular biomarkers for use in clinical practice. Recently, the discovery of cancer biomarkers has become a major focus of cancer research and there are thousands of publications on cancer biomarkers. The ideal biomarkers for cancer have applications in determining predisposition, early detection, assessment of prognosis, and drug response. The biomarker that serves as a target for drug development would have an additional advantage. Desirable characteristics of molecular markers for cancer are postulated, but no biomarker meets these ideal characteristics. Hence, there is an urgent need for cancer biomarkers with more accurate diagnostic capability, particularly for early-stage cancer.

Colorectal cancer (CRC) is the third most common malignancy in the world. In addition, there are approximately 1,000,000 new cases of CRC and 500,000 deaths associated with CRC each year. Indeed, CRC represents one of the primary causes of cancer deaths in Europe and the United States [1]. In Asia, including Japan, CRC is the fourth leading cause of mortality by cancer, and its incidence is increasing [2]. CRC develops slowly via a progressive accumulation of genetic mutations. Therefore, the risk of recurrence and subsequent death due to CRC is closely related to the stage of the disease at the time of the first diagnosis. Recent studies have shown that shifting the detection of the disease to an earlier stage via mass screening and intervening at early stage can reduce the risk of death from CRC $[3,4]$. These findings thus suggest the clinical need for biomarkers for early detection of CRC.

Biomarkers are used as indicators of a biological state of tissues. Therefore, biomarkers have characteristics that enable them to be objectively measured and evaluated as indicators of normal biological processes, pathogenic processes, or pharmacologic responses to a therapeutic intervention. One of the key requirements of biomarkers for detecting CRC is that it must allow detection of the 
disease at earlier stages. Such tests using biomarkers should have high sensitivity and specificity, while producing a low number of false-negative and false-positive results, to prevent subjecting healthy individuals to unnecessary colonoscopies. Colonoscopy offers significant improvements in the detection rates for CRC, but the diagnostic value of this is limited in relation to costs, risks, and inconvenience [5]. Non-invasive biomarkers have the potential to greatly enhance screening acceptance. Several non-invasive tests for detecting CRC are available, of which the fecal occult blood test (FOBT) is the most commonly used [6,7]. However, this test lacks sensitivity as well as specificity for screening an average risk population. Thus, novel CRC biomarkers that will further enhance the detection of the disease and trigger follow-up colonoscopies when necessary should be developed. In addition to such detection biomarkers, prognostic markers which can predict the likely course of the cancer, stratification markers which can predict the likely response to drugs prior to beginning treatment, and efficacy markers which can monitor the efficacy of drugs treatment may also reduce the mortality rate of CRC.

Table 2. Molecular biomarkers for the detection of CRC.

\begin{tabular}{|c|c|c|c|}
\hline Clinical use & Subjects & Types & Potential markers \\
\hline \multirow{3}{*}{ In use } & Stool & Protein & Fecal hemoglobin \\
\hline & \multirow{2}{*}{ Serum } & Protein & CEA \\
\hline & & Carbohydrate & CA19.9 \\
\hline \multirow{5}{*}{$\begin{array}{c}\text { Clinical } \\
\text { validation }\end{array}$} & \multirow{4}{*}{ Stool } & DNA & K-ras \\
\hline & & DNA & $A P C$ \\
\hline & & DNA & L-DNA \\
\hline & & DNA & p53 \\
\hline & Serum & Protein & TIMP-1 \\
\hline \multirow{15}{*}{$\begin{array}{c}\text { Preclinical } \\
\text { development }\end{array}$} & \multirow{13}{*}{ Serum } & Protein & Spondin-2, DcR3, Trail-R2, Reg IV, MIC1 \\
\hline & & Protein & PSME3 \\
\hline & & Protein & NNMT \\
\hline & & Protein & CRMP-2 \\
\hline & & Protein & SELDI (apolipoprotein C1, C3a-desArg, $\alpha 1$-antitrypsin, transferring) \\
\hline & & Protein & HNP 1-3 \\
\hline & & Protein & MIF \\
\hline & & Protein & M-CSF \\
\hline & & Protein & M2-PK \\
\hline & & Protein & Prolactin \\
\hline & & Protein & CCSA-2, $-3,-4$ \\
\hline & & Protein & MMP-9, -7 \\
\hline & & Protein & Laminin \\
\hline & Plasma & DNA & Septin 9 \\
\hline & WBC & DNA & 5-gene panel (CDA, BANK1, BCNP1, MS4A1, MGC20553) \\
\hline
\end{tabular}

Recent advances in genomics and proteomics have contributed to our understanding of the natural history of cancers. Genomic techniques, such as DNA microarray analysis and proteomic methods, for example, 2-dimensional electrophoresis and mass spectrometry, are now commonly used to evaluate the expression profiles of genes and proteins in cancer cells, their surrounding tissues, and body 
fluids [8]. Identification of genes and/or proteins that are characteristic of the development of cancer can potentially uncover biomarkers that will aid in the diagnosis of CRC. In this review, we will focus on potential non-biomarkers which have recently been discovered and non-invasive biomarkers which are currently being used in clinical settings (Table 2 ).

\section{Fecal Markers}

\subsection{Fecal Hemoglobin}

Stool-based detection of CRC is quite simple, inexpensive, and the least invasive method of screening available [9]. FOBT detecting hemoglobin enzymatically or immunologically is the most widely used screening modality for CRC and [10]. Enzymatic FOBT measures the peroxidase-like activity of hemoglobin originating from any source. Therefore, enzymatic FOBT is susceptible to bleeding from both colorectal and upper gastrointestinal tracts. In addition, the ingestion of certain foods (red meats, fruits and vegetables) and medicines (non-steroidal anti-inflammatory drugs) led also to false-positive results. Immunological FOBT using antibodies which specifically detect human hemoglobin is not impacted by plant peroxidase in the diet. An important limitation of the FOBT is the relatively poor sensitivity at detecting early-stage lesions. Low sensitivity of the FOBT for the detection of colorectal neoplasms is reported to be $\sim 10 \%$ of adenomas and 40 85\% of CRCs. In fact, randomized clinical trials indicated that FOBT is not very reliable and that it only reduces CRC mortality by $30 \%[3,11]$.

\subsection{Genes and Epigenetic Markers}

Cryptal cells (colonocytes) are shed into the fecal stream and provide informative materials that can be used to detect genes and epigenetic markers in feces [12]. Unlike fecal blood, cryptal cells are shed continuously. Furthermore, the shedding of cancer cells from CRC occurs more frequently than from normal colonic epithelium. Fecal cells including cancer cells can be assessed by analyzing DNA mutations for targets such as K-ras, p53, and adenomatous polyposis coli (APC), by analyzing epigenetic markers such as microsatellite instability (MSI), or by measuring unfragmented long-form DNA (L-DNA).

$\mathrm{K}$-ras, encoding a Ras family protein, functions as a guanine nucleotide binding protein that is involved in a signal transduction pathway including the phosphatidylinositol-3-kinase and serine/threonine protein kinase B pathways [13]. K-ras mutations are found in 40-50\% of sporadic colon cancers and adenomas [14]. In addition, K-ras mutations being present in aberrant crypt foci, which are putative pre-cancerous lesions, are reported to be found in 13-95\% of CRC [15-18]. Thus, K-ras mutations might be an important early event in colorectal carcinogenesis.

p53 encoding a tumor suppressor protein which regulates the expression of genes involved in apoptosis, angiogenesis, the cell cycle and maintenance of the genome [19]. Approximately half of human cancers contain mutated p53 genes, and 30-60\% of CRCs have mutations in the gene [20]. The mutations depend on the stage, grade and location of the cancer. The mutations appear to be at relatively late stage of colorectal carcinogenesis, and altered p53 has only modest impact on the 
outcome of CRC. Therefore, the relatively low mutation rate of p53 at early-stage limits the use in DNA-based detection of CRC.

APC protein is another tumor suppressor which assembles on a scaffold protein, axin, with $\beta$-catenin and glycogen synthase kinase $3 \beta$ to coordinate the regulation of $\beta$-catenin signaling [21]. Inactivation of the APC protein is responsible for both inherited and sporadic types of CRC. Like $\mathrm{K}$-ras, $A P C$ mutation appears to be an early-genetic event during the progression from adenoma to adenocarcinoma, suggesting its potential for use as a screening biomarker. However, unlike K-ras, the mutations are distributed throughout the coding region, thereby making it technically difficult and time consuming to detect all of the potential mutations during screening for CRC [22,23].

Microsatellites are stretches of short DNA sequences which contain a motif of 1-5 nucleotides with tandem repeats [24]. The most common microsatellite in human DNA is a dinucleotide repeat of cytosine and adenine. These tandem repeats occur throughout the human genome. MSI occurs when microsatellites undergo changes in length. MSI is observed in approximately $15 \%$ of the CRC tumors. Tumors with MSI have better prognosis than stage-matched tumors with stable microsatellite [25]. In sporadic CRC, MSI most commonly occurs due to epigenetic silencing of the DNA mismatch repair gene, MLH1 [26]. There are several MSI markers, among which BAT26 is probably the most widely used.

Shedding of cryptal cells is a normal consequence of exfoliation [27]. Untransformed cryptal cells are shed continuously from the colonic mucosa. These cells usually undergo apoptosis. Conversely, malignant CRC cells shed from tumor mass have a decreased rate of apoptosis relative to normal cryptal cells, which facilitate detection of intact genomic DNA (L-DNA) as a potential stool-based marker. Boynton [28] amplified six genomic fragments of different length from each of four different genetic loci (APC, p53, BRCA1, and BRCA2) using fecal specimens collected from 25 CRC patients and 77 controls. In this study, when a positive L-DNA was defined as $>18$ bands detected from a possible 24 bands ( 4 loci $\times 6$ fragments), the specificity for CRC detection was $97 \%$ and the sensitivity was $57 \%$.

A large population-based study revealed that a fecal DNA panel consisting of 21 mutations (three in the K-ras gene, 10 in the $A P C$ gene, and eight in the $p 53$ gene; the MSI markers of BAT-26; and L-DNA) detects a greater proportion of CRC than FOBT without compromising specificity [29]. In addition, the sensitivity of the fecal DNA panel was $52 \%$ for invasive CRC and $41 \%$ for invasive CRC plus adenomas with high-grade dysplasia, whereas that of the FOBT was 13\% for the former and $14 \%$ for the latter. In subjects with negative findings on colonoscopy, the DNA panel had a specificity of $94 \%$, whereas the FOBT had a specificity of $95 \%$. The results of the study clearly indicate that the DNA panel has a greater sensitivity than the FOBT without reduced specificity.

\section{Serum or Blood Markers}

\section{1. $C E A$}

Carcinoembryonic antigen (CEA) is a high molecular weight glycoprotein belonging to the immunoglobulin superfamily. The carboxy-terminal of CEA contains a hydrophobic region which is modified to provide a glycosyl phosphatidylinositol link to the cell membrane. While the presence can 
be determined in biopsy samples, it is usually identified in serum. This protein has been used for many years as a biomarker of CRC as well as cancers developing in other tissues [30]. High CEA levels are specifically associated with CRC progression, and increased levels of the marker are expected to fall following CRC surgery [31]. However, even in the absence of cancer, high CEA levels may also occur in response to inflammatory conditions, such as hepatitis, inflammatory bowel disease (IBD), pancreatitis, and obstructive pulmonary disease. In addition, CEA may not be elevated when CRC is at advanced stage. Thus, CEA does not provide sufficient sensitivity and reliability for the early detection of CRC. The potential value of the CEA test lies in its use to measure the course of the progression of cancer as a prognostic marker. CRC patients with higher CEA levels have poorer prognosis.

\subsection{CA $19-9$}

Carbohydrate antigen (CA) 19-9, which is the second most investigated gastrointestinal tumor marker, is known to be a sialylated Lewis-a antigen [32]. CA 19-9 was originally defined by a monoclonal antibody produced by hybridoma prepared from the spleen cells of mice immunized with the human CRC cell line, SW 1116. Although CA 19-9 is the best marker available for pancreatic adenocarcinoma, CA 19-9 is less sensitive than CEA for CRC and also gives less information than CEA [33]. Other carbohydrate antigens, such as CA 50, CA 195, CA 242, CA M26, CA M25, CA M43 and CA 72-4, have also been evaluated extensively [34], but, due to their sensitivity, stage dependency and specificity, these antigens are not useful markers for the detection of CRC.

\subsection{Tissue Inhibitor of Metalloproteinase Type 1}

Tissue inhibitor of metalloproteinase type (TIMP)-1 is a multifunctional glycoprotein which inhibits most matrix metalloproteinases (MMPs). The total levels of TIMP-1 in patients with CRC are significantly greater when compared to that of healthy blood donors who have a very narrow range of plasma TIMP-1 levels [35,36]. More importantly, TIMP-1 is capable of being detected at early stages of CRC. Conversely, plasma levels of total TIMP-1 in patients with colonic adenomas, IBD or primary breast cancer, do not increase [37]. Preoperative TIMP-1 levels were proposed as a stage-independent prognostic biomarker for CRC in two independent studies [38,39]. The results of these studies, however, indicated that elevation of TIMP-1 was restricted to advanced stages of CRC. Additional studies are required to validate the use of TIMP-1 for both early diagnosis and evaluation of the prognosis of CRC.

\subsection{Five-Serum-Marker Panel (Spondin-2, DcR3, Trail-R2, Reg IV, MIC 1)}

Four serum biomarkers, spondin-2, tumor necrosis factor receptor superfamily member 6B (DcR3), TRAIL receptor 2 (TRAIL-R2) and Reg IV were recently evaluated in 600 serum samples. All four markers, as well as a fifth marker, macrophage inhibitory cytokine 1 (MIC1), were elevated in patients with CRC when compared to normal controls and patients with benign diseases. Additionally, this five-serum biomarker panel may have better sensitivity and specificity than CEA to improve the detection rate of early stage CRC. 


\subsection{Nicotinamide N-methyltransferase and Proteasome Activator Complex Subunit 3}

To analyze 16 matched $\mathrm{CRC}$ and adjacent normal tissue samples, two-dimensional gel electrophoresis and mass spectrometry were used. Then proteins found to be elevated in cancer tissue were further validated with serum samples. Elevated levels of nicotinamide N-methyl-transferase (NNMT) and proteasome activator complex subunit 3 (PSME3), which are not predicted to be secreted, were found in serum from patients with CRC [40,41]. Validation studies using 109 CRC samples, 317 healthy control samples, and 87 samples from patients with benign large bowel diseases revealed that the diagnostic accuracy of PSME3 was similar to that of CEA, and that NNMT was better than CEA at detecting CRC.

\subsection{Collapsin Response Mediator Protein-2}

By analyzing the secretomes of 21 cancer cell lines derived from 12 cancer types, collapsin response mediator protein-2 (CRMP-2) was identified to be a potential CRC biomarker in the serums of 201 CRC patients and 210 healthy controls [42]. The use of CRMP-2 alone showed better sensitivity, but poorer specificity than CEA. Combined detection using CEA and CRMP-2 however produced better sensitivity (77\%) and specificity (95\%) than detection using either of these markers alone (43 and 61\% sensitivity, respectively; 87 and 65\% specificity, respectively). Thus, CRMP-2 might be a valuable serum marker when used in combination with CEA.

\section{MicroRNA}

For the past decade, the development of genomic technology has revolutionized modern biological research and drug discovery. Functional genomic analyses enable biologists to perform analysis of genetic events on a global scale and they have been widely used in gene discovery, biomarker determination, disease classification, and drug target identification. In this article, we provide an overview of the current and emerging tools involved in genomic studies, including expression arrays, microRNA (miRNA) arrays, array CGH, ChIP-on-chip, methylation arrays, mutation analysis, genome-wide association studies, proteomic analysis, integrated functional genomic analysis and related bioinformatic and biostatistical analyses [43].

Post-transcriptional regulation of gene expression by miRNA has recently attracted major interest among cancer researchers in relation to its involvement in cancer development. More than 1000 miRNAs are expressed in human cells, some tissue or cell type specific, others considered as house-keeping molecules. Functions and direct mRNA targets for some miRNAs have been relatively well studied over the last years. Every miRNA potentially regulates the expression of numerous protein-coding genes (tens to hundreds), but it has become increasingly clear that not all miRNAs are equally important; diverse high-throughput screenings of various systems have identified a limited number of key functional miRNAs over and over again. Particular miRNAs emerge as principal regulators that control major cell functions in various physiological and pathophysiological settings [44]. Altered miRNAs are reported in cancers of several tissues, including colon [45-47], liver [48], prostate [49], esophagus [50], brain [51], pancreas [52], breast [53], and chronic degenerative disease [54]. 
As to CRC, Dr. Nakagama's group [55,56] has demonstrated that Staphylococcal nuclease homology domain 1 (SND1), a component of RISC, is frequently up-regulated in human colon cancers and also chemically-induced colon cancers in animals, as well as in preneoplastic lesions of the colon. Overexpression of SND1 in colon cancer cells caused down-regulation of APC and activation of the Wnt signaling pathway as a consequence, without altering APC mRNA levels. Post-transcriptional regulation of gene expression by SND1 was suggested to be mediated by miRNA through the 3'-UTR containing the miRNA target sequence. As for the miRNA expression profile, miR-34a was among the list of down-regulated miRNA in human colon cancer, suggesting its tumor suppressive role in colon carcinogenesis. Expression of miR-34a is tightly regulated by p53, and ectopic expression of miR-34a in colon cancer cells causes remarkable reduction of cell proliferation and induces senescence-like phenotypes. miR-34a also down-regulates silent information regulator 1 (SIRT1), which is a class III histone deacetlylase and known to be a negative regulator of p53 through the modulation of acetylation at K382 of p53, and participates in the positive feedback loop of the p53 tumor suppressor network. Other investigators [57] also suggested tumor suppressor functions of miR-34a, in part, through a SIRT1-p53 pathway. Recently, miRNA expression in CRC has been found to be associated with microsatellite instability (MSI) subgroups, including low MSI and HNPCC-associated cancers [58]. Thus, miRNA are potential diagnostic and prognostic markers (Table 3), as well as therapeutic targets for CRC.

Table 3. miRNA related to prognosis of cancer.

\begin{tabular}{|c|c|c|}
\hline Cancers & miRNA & Authors and Ref. nos. \\
\hline \multirow{10}{*}{ Lung cancer } & hsa-let-7 & [59] \\
\hline & hsa-let-7a-2 & \multirow{2}{*}{ [60] } \\
\hline & hsa-miR-155 & \\
\hline & hsa-miR-196a2 & {$[61]$} \\
\hline & hsa-miR-221 & \multirow{5}{*}[62]{} \\
\hline & hsa-let-7a & \\
\hline & hsa-miR-137 & \\
\hline & hsa-miR-372 & \\
\hline & hsa-miR-182* & \\
\hline & hsa-miR-21 & {$[63]$} \\
\hline Hepatocellular carcinoma & hsa-miR-125b & [64] \\
\hline Breast cancer & hsa-miR-21 & {$[65]$} \\
\hline Gastric cancer & hsa-miR-21 & {$[66]$} \\
\hline \multirow{2}{*}{ Colorectal cancer } & hsa-miR-21 & {$[67]$} \\
\hline & hsa-miR-106a & {$[68]$} \\
\hline \multirow{2}{*}{ Head and neck cancer } & hsa-miR-7d & \multirow{2}{*}{ [69] } \\
\hline & hsa-miR-205 & \\
\hline Pancreatic cancer & hsa-miR-21 & {$[70]$} \\
\hline Acute myelogenous leukemia & hsa-miR-181 family & [71] \\
\hline Chronic lymphocytic leukemia & hsa-miR-1-miR-15a & {$[72]$} \\
\hline Ovarian cancer & hsa-let-7a-3 & [73] \\
\hline Esophageal cancer & hsa-miR-103 / 107 & [74] \\
\hline
\end{tabular}




\section{Other Potential Biomarkers}

Habermann demonstrated that $\mathrm{C} 3 \mathrm{a}-\mathrm{des} A r g$ is present at significantly higher levels in serum from patients with colorectal adenomas and carcinomas than in serum from healthy individuals [75]. Specifically, in a blinded validation study $(n=59)$, the use of C3a-desArg alone predicted the presence of CRC with a sensitivity of $97 \%$ and a specificity of $96 \%$.

Analyzing the protein profiles of colon cancer serum and protein profiles of CRC tumors demonstrated that human neutrophil peptides (HNP)-1, HNP-2 and HNP-3, also known as a-defensin-1, adefensin-2, and a-defensin-3, are up-regulated in CRC patients [76.77]. Indeed, the HNP1-3 level in the serum of 48 CRC patients and 42 normal controls was capable of identifying CRC with a sensitivity of $69 \%$ and a specificity of $100 \%$.

The gene expression level of macrophage migration inhibitory factor (MIF) is elevated in CRC tissues, suggesting the use of the protein as a potential biomarker for CRC. In an analysis of serum samples of 129 patients with colon cancer and 53 healthy control subjects, the serum MIF level was found to be significantly increased in patients with CRC [78]. Although the specificity of MIF is not as high as that of CEA (90.6\% vs. 100.0\%), MIF is more sensitive during early cancer detection (47.3\% vs. 29.5\%), which suggests that MIF may be used as a diagnostic marker in CRC.

The serum levels of both macrophage-colony stimulating factor (M-CSF) and granulocyte-colony stimulating factor are significantly higher in CRC patients than in healthy subjects [79,80]. In addition, serum levels of M-CSF are more associated with lymph node metastasis than CEA and CA 19-9, which suggests that serum M-CSF elevation in CRC patients might help predict the risk of lymph node metastasis of this tumor. M-CSF may offer additional information to that presented by classic prognostic factors.

Prolactin that is synthesized by the anterior pituitary gland is a hormone with multiple biological actions and is elevated in patients with CRC. A study that evaluated 47 CRC patients and 51 healthy controls revealed that prolactin can predict CRC with a sensitivity and specificity of $77 \%$ and $98 \%$, respectively [81].

M2-pyruvate kinase is an isoform of glycolytic enzyme pyruvate kinase. Although this protein is a cytosolic enzyme, it is liberated into circulation via an unknown mechanism. It is suggested that M2-pyruvate kinase is released into circulation from dying cancer cells. M2-pyruvate may thus be a useful marker for the detection of CRC. Two independent studies revealed that the use of M2-pyruvate kinase for the detection of CRC has a sensitivity of $48-58 \%$ and a specificity of $90-95 \%$. Further, when combined with CEA, the sensitivity of M2-pyruvate increases without decreasing the specificity [82,83].

Recent evidence suggests that the assessment of epigenetic events is one of the most promising means of identifying biomarker candidates for the early detection of cancer. DNA methylation, in which cytosines within the palindromic dinucleotide 5'-CpG-3' sequence are methylated, shapes the chromatin structure of DNA according to its functional state $[84,85]$. The cancer genome is frequently characterized by hypermethylation of specific genes. Therefore, epigenomics AG has developed a blood test for CRC that is based on methylation of SEPT9, NGFR and TMEEF2 [86]. The evaluation study of this test, using free-floating DNA extracted from plasma samples of 133 CRC patients and 179 healthy controls, in the same age range, to determine the methylation levels, using restriction 
enzyme-based qPCR, revealed that the biomarker with the highest performance was SEPT9, which was capable of detecting CRC with a specificity and sensitivity of $95 \%$ and $52 \%$, respectively, when a cutoff of $0.011 \mu \mathrm{g} / \mathrm{L}$ of methylated SEPT9 DNA was used.

Gene expression patterns in the peripheral blood reflect changes that occur within the cells and tissues of the body [86]. Han [87] extracted total RNA from the white blood cells of peripheral blood and identified differentially regulated genes using a microarray. Specifically, they used a panel comprised of five genes including B-cell scaffold protein with ankyrin repeats 1 (BANKI), B-cell novel protein 1 (BCNPI), cytidine deaminase (CDS), FERM domain containing 3 (MGC20553), and membrane-spanning 4-domains, subfamily A, member 1 (MS4AI), to detect CRC. This test had a sensitivity of $88-94 \%$ and a specificity of $64-77 \%$.

Three proteins, colon cancer-specific antigen (CCSA)-2, CCSA-3 and CCSA-4, have shown promise as markers for the detection of CRC. Using a cutoff value of $2 \mu \mathrm{g} / \mathrm{mL}$ for CCSA-3, both CRC and advanced adenoma were detected with $89 \%$ sensitivity and $82 \%$ specificity [88]. When CCSA-4 was used with a cutoff value of $0.3 \mu \mathrm{g} / \mathrm{mL}$, the sensitivity and specificity was $85 \%$ and $91 \%$, respectively. The use of CCSA-2 at a cutoff of $10.8 \mu \mathrm{g} / \mathrm{mL}$ had an overall specificity of $78 \%$ and sensitivity of $97 \%$ when used on separate individuals with advanced adenomas and CRC from normal, hyperplastic polyp, and adenoma populations [89].

Remodeling of the extracellular matrix is important in the development of epithelial malignancies, and several extracellular matrix proteins that can be liberated into circulation have been evaluated as potential biomarkers. The results of these evaluations have revealed that the serum levels of MMP9 and MMP7 depend on the presence of CRC [90,91]. In addition, serum laminin and MMP7 can be used as independent prognostic markers of CRC [91,92].

However, large scale clinical studies are required to refine and validate the diagnostic accuracy of the findings mentioned above.

\section{Conclusions}

Cancer biomarkers and characteristics of an ideal biomarker for CRC are discussed in this review, as well as technologies for their detection. The focus of this article is on the use of biomarkers for anticancer drug development and clinical applications, including determination of prognosis as well as monitoring of response to therapy. Types of biomarkers include serum/blood markers, fecal markers and miRNA. Currently, the FOBT is the only screening modality for CRC. DNA-based fecal markers are promising but are not widely used in clinical settings. In addition, a lack of sensitivity and specificity preclude the use of all existing serum markers for the early detection of CRC. CEA is used to monitor therapy in advanced CRC, and the pre-operative level of CEA is used to provide prognostic information. However, there is insufficient evidence for routine use of other classic serum markers such as carbohydrate antigens and TIMP-1. Therefore, large scale validation studies are required to evaluate the potential for the use of biomarkers that have recently been discovered through '-omics' technology. Within clinical research, oncology is expected to have the largest gains from biomarkers over the next five to ten years. Development of personalized medicine for cancer is closely linked to biomarkers, which may serve as the basis for diagnosis, drug discovery and monitoring of diseases. A major challenge in development of cancer biomarkers will be the integration of proteomics with 
genomics and metabolomics data and their functional interpretation in conjunction with clinical data and epidemiology [93].

\section{Acknowledgements}

This review was based on studies supported in part by a Grant-in-Aid for the 3rd Term Comprehensive 10-Year Strategy for Cancer Control from the Ministry of Health, Labour and Welfare of Japan; the Grant-in-Aid for Cancer Research from the Ministry of Health, Labour and Welfare of Japan; the Grants-in-Aid for Scientific Research (Nos. 18592076, 17015016 and 18880030) from the Ministry of Education, Culture, Sports, Science and Technology of Japan; and the grant (H2010-12) for the Project Research from High-Technology Center of Kanazawa Medical University.

\section{References}

1. Bingham, S.; Riboli, E. Diet and cancer-the european prospective investigation into cancer and nutrition. Nat. Rev. Cancer 2004, 4, 206-215.

2. Sung, J.J.; Lau, J.Y.; Goh, K.L.; Leung, W.K. Increasing incidence of colorectal cancer in Asia: Implications for screening. Lancet Oncol. 2005, 6, 871-876.

3. Hardcastle, J.D.; Chamberlain, J.O.; Robinson, M.H.; Moss, S.M.; Amar, S.S.; Balfour, T.W.; James, P.D.; Mangham, C.M. Randomised controlled trial of faecal-occult-blood screening for colorectal cancer. Lancet 1996, 348, 1472-1477.

4. Kronborg, O.; Fenger, C.; Olsen, J.; Jorgensen, O.D.; Sondergaard, O. Randomised study of screening for colorectal cancer with faecal-occult-blood test. Lancet 1996, 348, 1467-1471.

5. Winawer, S.; Fletcher, R.; Rex, D.; Bond, J.; Burt, R.; Ferrucci, J.; Ganiats, T.; Levin, T.; Woolf, S.; Johnson, D.; Kirk, L.; Litin, S.; Simmang, C. Colorectal cancer screening and surveillance: Clinical guidelines and rationale-Update based on new evidence. Gastroenterology 2003, 124, 544-560.

6. Booth, R.A. Minimally invasive biomarkers for detection and staging of colorectal cancer. Cancer Lett. 2007, 249, 87-96.

7. Habermann, J.K.; Bader, F.G.; Franke, C.; Zimmermann, K.; Gemoll, T.; Fritzsche, B.; Ried, T.; Auer, G.; Bruch, H.P.; Roblick, U.J. From the genome to the proteome-biomarkers in colorectal cancer. Langenbecks Arch. Surg. 2008, 393, 93-104.

8. Kim, S.Y.; Hahn, W.C. Cancer genomics: Integrating form and function. Carcinogenesis 2007, 28, 1387-1392.

9. Duffy, M.J.; van Dalen, A.; Haglund, C.; Hansson, L.; Holinski-Feder, E.; Klapdor, R.; Lamerz, R.; Peltomaki, P.; Sturgeon, C.; Topolcan, O. Tumour markers in colorectal cancer: European Group on Tumour Markers (EGTM) guidelines for clinical use. Eur. J. Cancer 2007, 43, 1348-1360.

10. Huang, C.S.; Lal, S.K.; Farraye, F.A. Colorectal cancer screening in average risk individuals. Cancer Causes Control 2005, 16, 171-188.

11. Mandel, J.S.; Bond, J.H.; Church, T.R.; Snover, D.C.; Bradley, G.M.; Schuman, L.M.; Ederer, F. Reducing mortality from colorectal cancer by screening for fecal occult blood. Minnesota colon cancer control study. N. Engl. J. Med. 1993, 328, 1365-1371. 
12. Loktionov, A.; O'Neill, I.K.; Silvester, K.R.; Cummings, J.H.; Middleton, S.J.; Miller, R. Quantitation of DNA from exfoliated colonocytes isolated from human stool surface as a novel noninvasive screening test for colorectal cancer. Clin. Cancer Res. 1998, 4, 337-342.

13. Shaw, R.J.; Cantley, L.C. Ras, PI(3)K and mTOR signalling controls tumour cell growth. Nature 2006, 441, 424-430.

14. Fearon, E.R.; Vogelstein, B. A genetic model for colorectal tumorigenesis. Cell 1990, 61, $759-767$.

15. Losi, L.; Roncucci, L.; di Gregorio, C.; de Leon, M.P.; Benhattar, J. K-ras and p53 mutations in human colorectal aberrant crypt foci. J. Pathol. 1996, 178, 259-263.

16. Shivapurkar, N.; Huang, L.; Ruggeri, B.; Swalsky, P.A.; Bakker, A.; Finkelstein, S.; Frost, A.; Silverberg, S. K-ras and p53 mutations in aberrant crypt foci and colonic tumors from colon cancer patients. Cancer Lett. 1997, 115, 39-46.

17. Smith, A.J.; Stern, H.S.; Penner, M.; Hay, K.; Mitri, A.; Bapat, B.V.; Gallinger, S. Somatic APC and K-ras codon 12 mutations in aberrant crypt foci from human colons. Cancer Res. 1994, 54, 5527-5530.

18. Takahashi, M.; Wakabayashi, K. Gene mutations and altered gene expression in azoxymethaneinduced colon carcinogenesis in rodents. Cancer Sci. 2004, 95, 475-480.

19. Mills, A.A. p53: Link to the past, bridge to the future. Genes Dev. 2005, 19, 2091-2099.

20. Iacopetta, B. TP53 mutation in colorectal cancer. Hum. Mutat. 2003, 21, 271-276.

21. Hart, M.J.; de los Santos, R.; Albert, I.N.; Rubinfeld, B.; Polakis, P. Downregulation of betacatenin by human Axin and its association with the APC tumor suppressor, beta-catenin and GSK3 beta. Curr. Biol. 1998, 8, 573-581.

22. Ahlquist, D.A.; Skoletsky, J.E.; Boynton, K.A.; Harrington, J.J.; Mahoney, D.W.; Pierceall, W.E.; Thibodeau, S.N.; Shuber, A.P. Colorectal cancer screening by detection of altered human DNA in stool: Feasibility of a multitarget assay panel. Gastroenterology 2000, 119, 1219-1227.

23. Srivastava, S.; Verma, M.; Henson, D.E. Biomarkers for early detection of colon cancer. Clin. Cancer Res. 2001, 7, 1118-1126.

24. Dietmaier, W.; Wallinger, S.; Bocker, T.; Kullmann, F.; Fishel, R.; Ruschoff, J. Diagnostic microsatellite instability: Definition and correlation with mismatch repair protein expression. Cancer Res. 1997, 57, 4749-4756.

25. Ribic, C.M.; Sargent, D.J.; Moore, M.J.; Thibodeau, S.N.; French, A.J.; Goldberg, R.M.; Hamilton, S.R.; Laurent-Puig, P.; Gryfe, R.; Shepherd, L.E.; Tu, D.; Redston, M.; Gallinger, S. Tumor microsatellite-instability status as a predictor of benefit from fluorouracil-based adjuvant chemotherapy for colon cancer. N. Engl. J. Med. 2003, 349, 247-257.

26. Esteller, M.; Levine, R.; Baylin, S.B.; Ellenson, L.H.; Herman, J.G. MLH1 promoter hypermethylation is associated with the microsatellite instability phenotype in sporadic endometrial carcinomas. Oncogene 1998, 17, 2413-2417.

27. Albaugh, G.P.; Iyengar, V.; Lohani, A.; Malayeri, M.; Bala, S.; Nair, P.P. Isolation of exfoliated colonic epithelial cells, a novel, non-invasive approach to the study of cellular markers. Int. J. Cancer 1992, 52, 347-350.

28. Boynton, K.A.; Summerhayes, I.C.; Ahlquist, D.A.; Shuber, A.P. DNA integrity as a potential marker for stool-based detection of colorectal cancer. Clin. Chem. 2003, 49, 1058-1065. 
29. Imperiale, T.F.; Ransohoff, D.F.; Itzkowitz, S.H.; Turnbull, B.A.; Ross, M.E. Fecal DNA versus fecal occult blood for colorectal-cancer screening in an average-risk population. N. Engl. J. Med. 2004, 351, 2704-2714.

30. Soreide, K.; Nedrebo, B.S.; Knapp, J.C.; Glomsaker, T.B.; Soreide, J.A.; Korner, H. Evolving molecular classification by genomic and proteomic biomarkers in colorectal cancer: Potential implications for the surgical oncologist. Surg. Oncol. 2009, 18, 31-50.

31. Duffy, M.J. Carcinoembryonic antigen as a marker for colorectal cancer: Is it clinically useful? Clin. Chem. 2001, 47, 624-630.

32. Magnani, J.L.; Nilsson, B.; Brockhaus, M.; Zopf, D.; Steplewski, Z.; Koprowski, H.; Ginsburg, V. A monoclonal antibody-defined antigen associated with gastrointestinal cancer is a ganglioside containing sialylated lacto-N-fucopentaose II. J. Biol. Chem. 1982, 257, 14365-14369.

33. Duffy, M.J. CA 19-9 as a marker for gastrointestinal cancers: A review. Ann. Clin. Biochem. 1998, 35, 364-370.

34. Hundt, S.; Haug, U.; Brenner, H. Blood markers for early detection of colorectal cancer: A systematic review. Cancer Epidemiol. Biomarkers Prev. 2007, 16, 1935-1953.

35. Holten-Andersen, M.N.; Murphy, G.; Nielsen, H.J.; Pedersen, A.N.; Christensen, I.J.; HoyerHansen, G.; Brunner, N.; Stephens, R.W. Quantitation of TIMP-1 in plasma of healthy blood donors and patients with advanced cancer. Br. J. Cancer 1999, 80, 495-503.

36. Sorensen, N.M.; Schrohl, A.S.; Jensen, V.; Christensen, I.J.; Nielsen, H.J.; Brunner, N. Comparative studies of tissue inhibitor of metalloproteinases-1 in plasma, serum and tumour tissue extracts from patients with primary colorectal cancer. Scand. J. Gastroenterol. 2008, 43, 186-191.

37. Holten-Andersen, M.N.; Fenger, C.; Nielsen, H.J.; Rasmussen, A.S.; Christensen, I.J.; Brunner, N.; Kronborg, O. Plasma TIMP-1 in patients with colorectal adenomas: A prospective study. Eur. J. Cancer 2004, 40, 2159-2164.

38. Holten-Andersen, M.; Christensen, I.J.; Nilbert, M.; Bendahl, P.O.; Nielsen, H.J.; Brunner, N.; Fernebro, E. Association between preoperative plasma levels of tissue inhibitor of metalloproteinases 1 and rectal cancer patient survival. A validation study. Eur. J. Cancer 2004, 40, 64-72.

39. Holten-Andersen, M.N.; Stephens, R.W.; Nielsen, H.J.; Murphy, G.; Christensen, I.J.; Stetler-Stevenson, W.; Brunner, N. High preoperative plasma tissue inhibitor of metalloproteinase-1 levels are associated with short survival of patients with colorectal cancer. Clin. Cancer Res. 2000, 6, 4292-4299.

40. Roessler, M.; Rollinger, W.; Mantovani-Endl, L.; Hagmann, M.L.; Palme, S.; Berndt, P.; Engel, A.M.; Pfeffer, M.; Karl, J.; Bodenmuller, H.; Ruschoff, J.; Henkel, T.; Rohr, G.; Rossol, S.; Rosch, W.; Langen, H.; Zolg, W.; Tacke, M. Identification of PSME3 as a novel serum tumor marker for colorectal cancer by combining two-dimensional polyacrylamide gel electrophoresis with a strictly mass spectrometry-based approach for data analysis. Mol. Cell Proteomics 2006, 5, 2092-2101.

41. Roessler, M.; Rollinger, W.; Palme, S.; Hagmann, M.L.; Berndt, P.; Engel, A.M.; Schneidinger, B.; Pfeffer, M.; Andres, H.; Karl, J.; Bodenmuller, H.; Ruschoff, J.; Henkel, T.; Rohr, G.; Rossol, S.; Rosch, W.; Langen, H.; Zolg, W.; Tacke, M. Identification of nicotinamide 
N-methyltransferase as a novel serum tumor marker for colorectal cancer. Clin. Cancer Res. 2005, $11,6550-6557$.

42. Wu, C.C.; Chen, H.C.; Chen, S.J.; Liu, H.P.; Hsieh, Y.Y.; Yu, C.J.; Tang, R.; Hsieh, L.L.; Yu, J.S.; Chang, Y.S. Identification of collapsin response mediator protein-2 as a potential marker of colorectal carcinoma by comparative analysis of cancer cell secretomes. Proteomics 2008, 8, 316-332.

43. Chen, X.; Jorgenson, E.; Cheung, S.T. New tools for functional genomic analysis. Drug. Discov. Today 2009, 14, 754-760.

44. Krichevsky, A.M.; Gabriely, G. miR-21: A small multi-faceted RNA. J. Cell Mol. Med. 2009, 13, 39-53.

45. Akao, Y.; Nakagawa, Y.; Naoe, T. MicroRNA-143 and -145 in colon cancer. DNA Cell Biol. 2007 26, 311-320.

46. Faber, C.; Kirchner, T.; Hlubek, F. The impact of microRNAs on colorectal cancer. Virchows Arch. 2009, 454, 359-367.

47. Yang, L.; Belaguli, N.; Berger, D.H. MicroRNA and colorectal cancer. World J. Surg. 2009, 33, 638-646.

48. Hoshida, Y.; Toffanin, S.; Lachenmayer, A.; Villanueva, A.; Minguez, B.; Llovet, J.M. Molecular classification and novel targets in hepatocellular carcinoma: Recent advancements. Semin. Liver Dis. 2010, 30, 35-51.

49. Sorensen, K.D.; Orntoft, T.F. Discovery of prostate cancer biomarkers by microarray gene expression profiling. Expert Rev. Mol. Diagn. 2010, 10, 49-64.

50. Kan, T.; Meltzer, S.J. MicroRNAs in Barrett's esophagus and esophageal adenocarcinoma. Curr. Opin. Pharmacol. 2009, 9, 727-732.

51. Novakova, J.; Slaby, O.; Vyzula, R.; Michalek, J. MicroRNA involvement in glioblastoma pathogenesis. Biochem. Biophys. Res. Commun. 2009, 386, 1-5.

52. Izumiya, M.; Okamoto, K.; Tsuchiya, N.; Nakagama, H. Functional screening using a microRNA virus library and microarrays: A new high-throughput assay to identify tumor-suppressive microRNAs. Carcinogenesis 2010, 31, in press.

53. Shi, M.; Guo, N. MicroRNA expression and its implications for the diagnosis and therapeutic strategies of breast cancer. Cancer Treat. Rev. 2009, 35, 328-334.

54. Ho, L.; Fivecoat, H.; Wang, J.; Pasinetti, G.M. Alzheimer's disease biomarker discovery in symptomatic and asymptomatic patients: Experimental approaches and future clinical applications. Exp. Gerontol. 2010, 45, 15-22.

55. Tazawa, H.; Tsuchiya, N.; Izumiya, M.; Nakagama, H. Tumor-suppressive miR-34a induces senescence-like growth arrest through modulation of the E2F pathway in human colon cancer cells. Proc. Natl. Acad. Sci. USA 2007, 104, 15472-15477.

56. Tsuchiya, N.; Ochiai, M.; Nakashima, K.; Ubagai, T.; Sugimura, T.; Nakagama, H. SND1, a component of RNA-induced silencing complex, is up-regulated in human colon cancers and implicated in early stage colon carcinogenesis. Cancer Res. 2007, 67, 9568-9576.

57. Yamakuchi, M.; Ferlito, M.; Lowenstein, C.J. miR-34a repression of SIRT1 regulates apoptosis. Proc. Natl. Acad. Sci. USA 2008, 105, 13421-13426. 
58. Earle, J.S.; Luthra, R.; Romans, A.; Abraham, R.; Ensor, J.; Yao, H.; Hamilton, S.R. Association of microRNA expression with microsatellite instability status in colorectal adenocarcinoma. $J$. Mol. Diagn. 2010, 12, in press.

59. Takamizawa, J.; Konishi, H.; Yanagisawa, K.; Tomida, S.; Osada, H.; Endoh, H.; Harano, T.; Yatabe, Y.; Nagino, M.; Nimura, Y.; Mitsudomi, T.; Takahashi, T. Reduced expression of the let7 microRNAs in human lung cancers in association with shortened postoperative survival. Cancer Res. 2004, 64, 3753-3756.

60. Yanaihara, N.; Caplen, N.; Bowman, E.; Seike, M.; Kumamoto, K.; Yi, M.; Stephens, R.M.; Okamoto, A.; Yokota, J.; Tanaka, T.; Calin, G.A.; Liu, C.G.; Croce, C.M.; Harris, C.C. Unique microRNA molecular profiles in lung cancer diagnosis and prognosis. Cancer Cell 2006, 9, 189-198.

61. Hu, Z.; Chen, J.; Tian, T.; Zhou, X.; Gu, H.; Xu, L.; Zeng, Y.; Miao, R.; Jin, G.; Ma, H.; Chen, Y.; Shen, H. Genetic variants of miRNA sequences and non-small cell lung cancer survival. $J$. Clin. Invest. 2008, 118, 2600-2608.

62. Yu, S.L.; Chen, H.Y.; Chang, G.C.; Chen, C.Y.; Chen, H.W.; Singh, S.; Cheng, C.L.; Yu, C.J.; Lee, Y.C.; Chen, H.S.; Su, T.J.; Chiang, C.C.; Li, H.N.; Hong, Q.S.; Su, H.Y.; Chen, C.C.; Chen, W.J.; Liu, C.C.; Chan, W.K.; Li, K.C.; Chen, J.J.; Yang, P.C. MicroRNA signature predicts survival and relapse in lung cancer. Cancer Cell 2008, 13, 48-57.

63. Markou, A.; Tsaroucha, E.G.; Kaklamanis, L.; Fotinou, M.; Georgoulias, V.; Lianidou, E.S. Prognostic value of mature microRNA-21 and microRNA-205 overexpression in non-small cell lung cancer by quantitative real-time RT-PCR. Clin. Chem. 2008, 54, 1696-1704.

64. Li, W.; Xie, L.; He, X.; Li, J.; Tu, K.; Wei, L.; Wu, J.; Guo, Y.; Ma, X.; Zhang, P.; Pan, Z.; Hu, X.; Zhao, Y.; Xie, H.; Jiang, G.; Chen, T.; Wang, J.; Zheng, S.; Cheng, J.; Wan, D.; Yang, S.; Li, Y.; Gu, J. Diagnostic and prognostic implications of microRNAs in human hepatocellular carcinoma. Int. J. Cancer 2008, 123, 1616-1622.

65. Yan, L.X.; Huang, X.F.; Shao, Q.; Huang, M.Y.; Deng, L.; Wu, Q.L.; Zeng, Y.X.; Shao, J.Y. MicroRNA miR-21 overexpression in human breast cancer is associated with advanced clinical stage, lymph node metastasis and patient poor prognosis. RNA 2008, 14, 2348-2360.

66. Chan, S.H.; Wu, C.W.; Li, A.F.; Chi, C.W.; Lin, W.C. miR-21 microRNA expression in human gastric carcinomas and its clinical association. Anticancer Res. 2008, 28, 907-911.

67. Schepeler, T.; Reinert, J.T.; Ostenfeld, M.S.; Christensen, L.L.; Silahtaroglu, A.N.; Dyrskjot, L.; Wiuf, C.; Sorensen, F.J.; Kruhoffer, M.; Laurberg, S.; Kauppinen, S.; Orntoft, T.F.; Andersen, C.L. Diagnostic and prognostic microRNAs in stage II colon cancer. Cancer Res. 2008, 68, 6416-6424.

68. Diaz, R.; Silva, J.; Garcia, J.M.; Lorenzo, Y.; Garcia, V.; Pena, C.; Rodriguez, R.; Munoz, C.; Garcia, F.; Bonilla, F.; Dominguez, G. Deregulated expression of miR-106a predicts survival in human colon cancer patients. Gene. Chromosome. Canc. 2008, 47, 794-802.

69. Childs, G.; Fazzari, M.; Kung, G.; Kawachi, N.; Brandwein-Gensler, M.; McLemore, M.; Chen, Q.; Burk, R.D.; Smith, R.V.; Prystowsky, M.B.; Belbin, T.J.; Schlecht, N.F. Low-level expression of microRNAs let-7d and miR-205 are prognostic markers of head and neck squamous cell carcinoma. Am. J. Pathol. 2009, 174, 736-745. 
70. Roldo, C.; Missiaglia, E.; Hagan, J.P.; Falconi, M.; Capelli, P.; Bersani, S.; Calin, G.A.; Volinia, S.; Liu, C.G.; Scarpa, A.; Croce, C.M. MicroRNA expression abnormalities in pancreatic endocrine and acinar tumors are associated with distinctive pathologic features and clinical behavior. J. Clin. Oncol. 2006, 24, 4677-4684.

71. Marcucci, G.; Radmacher, M.D.; Maharry, K.; Mrozek, K.; Ruppert, A.S.; Paschka, P.; Vukosavljevic, T.; Whitman, S.P.; Baldus, C.D.; Langer, C.; Liu, C.G.; Carroll, A.J.; Powell, B.L.; Garzon, R.; Croce, C.M.; Kolitz, J.E.; Caligiuri, M.A.; Larson, R.A.; Bloomfield, C.D. MicroRNA expression in cytogenetically normal acute myeloid leukemia. N. Engl. J. Med. 2008, 358, 1919-1928.

72. Calin, G.A.; Ferracin, M.; Cimmino, A.; Di Leva, G.; Shimizu, M.; Wojcik, S.E.; Iorio, M.V.; Visone, R.; Sever, N.I.; Fabbri, M.; Iuliano, R.; Palumbo, T.; Pichiorri, F.; Roldo, C.; Garzon, R.; Sevignani, C.; Rassenti, L.; Alder, H.; Volinia, S.; Liu, C.G.; Kipps, T.J.; Negrini, M.; Croce, C.M. A MicroRNA signature associated with prognosis and progression in chronic lymphocytic leukemia. N. Engl. J. Med. 2005, 353, 1793-1801.

73. Lu, L.; Katsaros, D.; de la Longrais, I.A.; Sochirca, O.; Yu, H. Hypermethylation of let-7a-3 in epithelial ovarian cancer is associated with low insulin-like growth factor-II expression and favorable prognosis. Cancer Res. 2007, 67, 10117-10122.

74. Guo, Y.; Chen, Z.; Zhang, L.; Zhou, F.; Shi, S.; Feng, X.; Li, B.; Meng, X.; Ma, X.; Luo, M.; Shao, K.; Li, N.; Qiu, B.; Mitchelson, K.; Cheng, J.; He, J. Distinctive microRNA profiles relating to patient survival in esophageal squamous cell carcinoma. Cancer Res. 2008, 68, 26-33.

75. Habermann, J.K.; Roblick, U.J.; Luke, B.T.; Prieto, D.A.; Finlay, W.J.; Podust, V.N.; Roman, J.M.; Oevermann, E.; Schiedeck, T.; Homann, N.; Duchrow, M.; Conrads, T.P.; Veenstra, T.D.; Burt, S.K.; Bruch, H.P.; Auer, G.; Ried, T. Increased serum levels of complement C3a anaphylatoxin indicate the presence of colorectal tumors. Gastroenterology 2006, 131, 1020-1029; quiz 1284.

76. Albrethsen, J.; Bogebo, R.; Gammeltoft, S.; Olsen, J.; Winther, B.; Raskov, H. Upregulated expression of human neutrophil peptides 1, 2 and 3 (HNP 1-3) in colon cancer serum and tumours: A biomarker study. BMC Cancer 2005, 5, 8.

77. Melle, C.; Ernst, G.; Schimmel, B.; Bleul, A.; Thieme, H.; Kaufmann, R.; Mothes, H.; Settmacher, U.; Claussen, U.; Halbhuber, K.J.; Von Eggeling, F. Discovery and identification of alpha-defensins as low abundant, tumor-derived serum markers in colorectal cancer. Gastroenterology 2005, 129, 66-73.

78. Lee, H.; Rhee, H.; Kang, H.J.; Kim, H.S.; Min, B.S.; Kim, N.K.; Kim, H. Macrophage migration inhibitory factor may be used as an early diagnostic marker in colorectal carcinomas. Am. J. Clin. Pathol. 2008, 129, 772-779.

79. Mroczko, B.; Groblewska, M.; Wereszczynska-Siemiatkowska, U.; Kedra, B.; Konopko, M.; Szmitkowski, M. The diagnostic value of G-CSF measurement in the sera of colorectal cancer and adenoma patients. Clin. Chim. Acta 2006, 371, 143-147.

80. Mroczko, B.; Groblewska, M.; Wereszczynska-Siemiatkowska, U.; Okulczyk, B.; Kedra, B.; Laszewicz, W.; Dabrowski, A.; Szmitkowski, M. Serum macrophage-colony stimulating factor levels in colorectal cancer patients correlate with lymph node metastasis and poor prognosis. Clin. Chim. Acta 2007, 380, 208-212. 
81. Soroush, A.R.; Zadeh, H.M.; Moemeni, M.; Shakiba, B.; Elmi, S. Plasma prolactin in patients with colorectal cancer. BMC Cancer 2004, 4, 97.

82. Schneider, J.; Bitterlich, N.; Schulze, G. Improved sensitivity in the diagnosis of gastro-intestinal tumors by fuzzy logic-based tumor marker profiles including the tumor M2-PK. Anticancer Res. 2005, 25, 1507-1515.

83. Zhang, B.; Chen, J.Y.; Chen, D.D.; Wang, G.B.; Shen, P. Tumor type M2 pyruvate kinase expression in gastric cancer, colorectal cancer and controls. World J. Gastroenterol. 2004, 10, 1643-1646.

84. Zhu, J.; Yao, X. Use of DNA methylation for cancer detection and molecular classification. $J$. Biochem. Mol. Biol. 2007, 40, 135-141.

85. Tost, J. DNA methylation: An introduction to the biology and the disease-associated changes of a promising biomarker. Methods Mol. Biol. 2009, 507, 3-20.

86. Lofton-Day, C.; Model, F.; Devos, T.; Tetzner, R.; Distler, J.; Schuster, M.; Song, X.; Lesche, R.; Liebenberg, V.; Ebert, M.; Molnar, B.; Grutzmann, R.; Pilarsky, C.; Sledziewski, A. DNA methylation biomarkers for blood-based colorectal cancer screening. Clin. Chem. 2008, 54, 414-423.

87. Han, M.; Liew, C.T.; Zhang, H.W.; Chao, S.; Zheng, R.; Yip, K.T.; Song, Z.Y.; Li, H.M.; Geng, X.P.; Zhu, L.X.; Lin, J.J.; Marshall, K.W.; Liew, C.C. Novel blood-based, five-gene biomarker set for the detection of colorectal cancer. Clin. Cancer Res. 2008, 14, 455-460.

88. Brunagel, G.; Vietmeier, B.N.; Bauer, A.J.; Schoen, R.E.; Getzenberg, R.H. Identification of nuclear matrix protein alterations associated with human colon cancer. Cancer Res. 2002, 62, 2437-2442.

89. Leman, E.S.; Schoen, R.E.; Magheli, A.; Sokoll, L.J.; Chan, D.W.; Getzenberg, R.H. Evaluation of colon cancer-specific antigen 2 as a potential serum marker for colorectal cancer. Clin. Cancer Res. 2008, 14, 1349-1354.

90. Hurst, N.G.; Stocken, D.D.; Wilson, S.; Keh, C.; Wakelam, M.J.; Ismail, T. Elevated serum matrix metalloproteinase 9 (MMP-9) concentration predicts the presence of colorectal neoplasia in symptomatic patients. Br. J. Cancer 2007, 97, 971-977.

91. Maurel, J.; Nadal, C.; Garcia-Albeniz, X.; Gallego, R.; Carcereny, E.; Almendro, V.; Marmol, M.; Gallardo, E.; Maria Auge, J.; Longaron, R.; Martinez-Fernandez, A.; Molina, R.; Castells, A.; Gascon, P. Serum matrix metalloproteinase 7 levels identifies poor prognosis advanced colorectal cancer patients. Int. J. Cancer 2007, 121, 1066-1071.

92. Saito, N.; Kameoka, S. Serum laminin is an independent prognostic factor in colorectal cancer. Int. J. Colorectal. Dis. 2005, 20, 238-244.

93. Jain, K.K. Cancer biomarkers: Current issues and future directions. Curr. Opin. Mol. Ther. 2007, 9, 563-571.

(C) 2010 by the authors; licensee MDPI, Basel, Switzerland. This article is an open access article distributed under the terms and conditions of the Creative Commons Attribution license (http://creativecommons.org/licenses/by/3.0/). 